\title{
Recurrent Childhood Cerebral Astrocytoma
}

National Cancer Institute

\section{Source}

National Cancer Institute. Recurrent Childhood Cerebral Astrocytoma. NCI Thesaurus.

Code C9191.

The reemergence of cerebral astrocytoma in childhood after a period of remission. 